\title{
Cardiopulmonary bypass increases pulmonary microvascular permeability through the Src kinase pathway: Involvement of caveolin-1 and vascular endothelial cadherin
}

\author{
JUNWEN ZHANG, ZHAOLEI JIANG, CHUNRONG BAO, JU MEI and JIAQUAN ZHU \\ Department of Cardiothoracic Surgery, Xinhua Hospital, School of Medicine, \\ Shanghai Jiao Tong University, Shanghai 200092, P.R. China \\ Received March 9, 2015; Accepted January 12, 2016
}

DOI: $10.3892 / \mathrm{mmr} .2016 .4831$

\begin{abstract}
Changes in pulmonary microvascular permeability following cardiopulmonary bypass (CPB) and the underlying mechanisms have not yet been established. Therefore, the aim of the present study was to elucidate the alterations in pulmonary microvascular permeability following CPB and the underlying mechanism. The pulmonary microvascular permeability was measured using Evans Blue dye (EBD) exclusion, and the neutrophil infiltration and proinflammatory cytokine secretion was investigated. In addition, the activation of Src kinase and the phosphorylation of caveolin-1 and vascular endothelial cadherin (VE-cadherin) was examined. The results revealed that CPB increased pulmonary microvascular leakage, neutrophil count and proinflammatory cytokines in the bronchoalveolar lavage fluid, and activated Src kinase. The administration of PP2, an inhibitor of Src kinase, decreased the activation of Src kinase and attenuated the increase in pulmonary microvascular permeability observed following CPB. Two important proteins associated with vascular permeability, caveolin-1 and VE-cadherin, were significantly activated at $24 \mathrm{~h}$ in the lung tissues following CPB, which correlated with the alterations in pulmonary microvascular permeability and Src kinase. PP2 administration inhibited their activation, suggesting that they are downstream factors of Src kinase activation. The data indicated that the Src kinase pathway increased pulmonary microvascular permeability following $\mathrm{CPB}$, and the activation of caveolin-1 and VE-cadherin may be involved. Inhibition of
\end{abstract}

Correspondence to: Dr Jiaquan Zhu, Department of Cardiothoracic Surgery, Xinhua Hospital, School of Medicine, Shanghai Jiao Tong University, 1665 Kongjiang Road, Shanghai 200092, P.R. China E-mail: dr_jiaquanzhu@yeah.net

Key words: pulmonary microvascular permeability, Src kinase pathway, caveolin-1, vascular endothelial-cadherin, cardiopulmonary bypass this pathway may provide a potential therapy for acute lung injury following cardiac surgery.

\section{Introduction}

Cardiopulmonary bypass (CPB) has been widely used in open heart surgery in the last six decades since John H. Gibbon invented the artificial heart and lung machine (1). With improvements in medical equipment and biomaterial technologies, including smaller prime volume circuits, more biocompatible surfaces and gas-permeable microporous membranes, the incidence of CPB-induced complications have significantly decreased $(2,3)$. However, CPB is known to activate systemic inflammatory response syndrome with acute lung injury that is associated with microvascular barrier injury (4). Numerous factors, including pulmonary hypoperfusion, induction of inflammatory mediators, hypothermia and blood contact with foreign surfaces during $\mathrm{CPB}$, contribute to the etiology of lung injury (5). Post-surgical lung injury predominantly consists of lung edema and hypoxia, which are associated with CPB-induced neutrophil infiltration and increased microvascular permeability (6).

The Src family is important in intracellular signal transduction in acute inflammatory responses $(7,8)$. Src is widely expressed by macrophages, monocytes, neutrophils, alveolar epithelial cells, endothelial cells and fibroblasts in the lung. It has been reported that Src is involved in the increase of lung vascular permeability in mice exposed to mechanical ventilation and hyperoxia-augmented ventilation $(9,10)$. Thus, the present study aimed to determine whether the Src kinase pathway is involved in CPB-induced proinflammatory cytokine secretion, neutrophil infiltration and microvascular hyperpermeability.

Caveolin-1, a member of the caveolin family, exists primarily in lung endothelial cells and type I epithelial cells and functions as a structural and signaling protein (11). It is required for the formation and trafficking of caveolae, the primary vesicular carriers and mechanism of transcellular macromolecule transport through the vascular endothelial barrier $(12,13)$. Vascular endothelial cadherin (VE-cadherin) is a cell-specific member of the cadherin protein family, which regulates endothelial adherens junctions $(14,15)$. The present study initially investigated the effects of CPB on pulmonary microvascular permeability, neutrophil infiltration 
and secretion of proinflammatory cytokines. Subsequently, the role of Src kinase activation, caveolin-1 and VE-cadherin phosphorylation in CPB was examined.

\section{Materials and methods}

Animals and drugs. A total of 460 male Sprague-Dawley rats, weighing $250 \pm 10 \mathrm{~g}$, age 10 weeks, were obtained from the Shanghai Experimental Animal Center (Shanghai, China) and used in all experiments. Animals were raised under standard conditions $\left(22^{\circ} \mathrm{C}, 33 \%\right.$ humidity) with a $12 \mathrm{~h}$ light/dark cycle. The study was performed in accordance with the National Institute of Health Guide for the Care and Use of Laboratory Animals (16) and with the approval of the research committee at Shanghai Jiaotong University (Shanghai, China). The non-specific Src kinase inhibitor 4-amino-5-(4-chlorophen yl)-7-(dimethylethyl)pyrazolo[3,4-d]pyrimidine (PP2) was purchased from Cayman Chemical Co. (Ann Arbor, MI, USA).

Experimental design. In order to examine the time course of pulmonary microvascular permeability, neutrophil infiltration and proinflammatory cytokine secretion, rats were randomly assigned to the following four groups ( $\mathrm{n}=10$ in each group): Sham group, CPB group, CPB + PP2 group and the untreated group. Rats in the sham group received similar surgery to the $\mathrm{CPB}$ and $\mathrm{CPB}+\mathrm{PP} 2$ group, however, no blood was drained from the rats. Rats in the $\mathrm{CPB}$ group received $\mathrm{CPB}$ surgery as described below. Rats in the $\mathrm{CPB}+\mathrm{PP} 2$ group received PP2 administration ( $1 \mathrm{mg} / \mathrm{kg}$, intraperitoneal injection) $30 \mathrm{~min}$ prior to CPB surgery. Rats in the untreated group received no treatment. In order to investigate the time course of Src kinase phosphorylation, rats were randomly assigned to five groups ( $\mathrm{n}=10$ in each group): Pre-CPB (baseline), $0 \mathrm{~h}$ after CPB, $12 \mathrm{~h}$ after CPB, $24 \mathrm{~h}$ after $\mathrm{CPB}$ and $48 \mathrm{~h}$ after CPB. To determine the alterations in VE-cadherin and caveolin-1 phosphorylation, rats were randomly assigned to five groups $(n=10$ in each group): Sham, $24 \mathrm{~h}$ after CPB, $24 \mathrm{~h}$ after $\mathrm{CPB}+1 \mathrm{mg} / \mathrm{kg}$ PP2, $24 \mathrm{~h}$ after $\mathrm{CPB}+2 \mathrm{mg} / \mathrm{kg} \mathrm{PP} 2$ and $24 \mathrm{~h}$ after $\mathrm{CPB}+4 \mathrm{mg} / \mathrm{kg}$ PP2.

$C P B$ procedure. The CPB procedure was performed according to the method described in our previous study (17). Initially, animals were anesthetized by intraperitoneal administration of butylone (60 mg/kg; Shanghai Experimental Animal Center) and then pentobarbital (3\%; $1.5 \mathrm{mg} / \mathrm{kg}$ body weight; Shanghai Experimental Animal Center) was continuously provided to maintain anesthesia. The right femoral artery was cannulated with a 24-gauge catheter (heparinized with polytetrafluoroethylene) to monitor arterial pressure. Following administration of heparin $(250 \mathrm{U} / \mathrm{kg})$, a 16-gauge catheter was advanced to the right atrium through the right jugular vein. A 22-gauge catheter was cannulated to the tail artery as an arterial infusion line.

As described in our previous study (17), the mini-CPB circuit consisted of a venous reservoir, a specially designed membrane oxygenator, a roller pump and sterile polyvinyl chloride tubing with an internal diameter of $3 \mathrm{~mm}$ for the venous and arterial lines. The roller pump was equipped with a silicone tube $15 \mathrm{~cm}$ in length with an internal diameter of $5 \mathrm{~mm}$. The membrane oxygenator was specially designed with a surface area for gas exchange of $0.05 \mathrm{~m}^{2}$ (Micro-1; Dongguan Kewei Medical Instrument Co., Ltd., Dongguan, China), with a total assembly dynamic priming volume of $\sim 2 \mathrm{ml}$. The CPB circuit was primed with $12 \mathrm{ml}$ of a solution of heparin $(250 \mathrm{U} / \mathrm{kg})$ and hetastarch. The blood was drained from the right atrium through the jugular vein catheter to a 5-ml sterile open reservoir using a siphon. A roller pump (BT00-300M; Baoding Lange Co., Ltd., Baoding, China) was used to drive the blood through silicone arterial inflow tubing and then return it to the tail artery.

Evans blue dye (EBD) exclusion analysis. Pulmonary microvascular injury was assessed by the extravasation of EBD into the lung parenchyma as described by Cavriani et al (18). EBD solution $(100 \mathrm{mg} / \mathrm{ml})$ was prepared in phosphate-buffered saline (PBS; pH 7.4) and intravenously injected at a dose of $30 \mathrm{mg} / \mathrm{kg}$, then allowed to circulate for $30 \mathrm{~min}$ prior to sacrifice by decapitation. The right lungs were then excised and flushed with cold PBS three times. Two samples of lung parenchyma were resected and weighed. One sample was dried in an oven $\left(60^{\circ} \mathrm{C}\right)$ for $72 \mathrm{~h}$ to obtain the dry weight. The other sample was homogenized in $5 \mathrm{ml}$ of formamide to extract EBD. This homogenate was then incubated at $60^{\circ} \mathrm{C}$ for $24 \mathrm{~h}$ and centrifuged at 4,000 $\mathrm{x} \mathrm{g}$ for $30 \mathrm{~min}$. The supernatant was then collected. The EBD optical density was measured at a wavelength of $620 \mathrm{~nm}$ using an EAR 340 mictrotiter plate reader (SLT-Lab Instruments, Salzburg, Austria). The concentration of EBD was calculated from a standard curve of EBD-formamide solutions. The dry/wet ratio of each lung sample was calculated and used in the final calculation of Evans blue extravasation. EBD was expressed as $\mu \mathrm{g}$ Evans blue/g dry weight.

Bronchoalveolar lavage fluid (BALF) collection and assays. At the time point of sample collection, animals were sacrificed by decapitation and the chest was opened. A cannula was then inserted into the left trachea. The left lung cavity was gently flushed with $500 \mu \mathrm{l}$ saline $\left(4^{\circ} \mathrm{C}\right)$ up to a total volume of $2 \mathrm{ml}$ to obtain BALF, which was then centrifuged at $400 \mathrm{xg}$ for $10 \mathrm{~min}$. The supernatant was used for the proinflammatory cytokine assay. The pelleted cells were re-suspended in PBS and then the neutrophil count was determined using a Hemovet HV950FS (CDC Technologies Inc., Oxford, CT, USA). ELISA kits (BioLegend, Inc., San Diego, CA, USA) were used to measure the levels of tumor necrosis factor (TNF)- $\alpha$, interleukin (IL)- $1 \beta$ and IL- 6 in the supernatants of BALF according to the manufacturer's protocol. The results were expressed as $\mathrm{pg} / \mathrm{ml}$ BALF.

Western blot analysis. Following collection of BALF, the lung tissues were washed in ice-cold saline, then homogenized in $4^{\circ} \mathrm{C}$ RIPA lysis buffer (Beyotime Institute of Biotechnology, Shanghai, China) with $1 \mathrm{mM}$ phenylmethanesulfonyl fluoride and centrifuged at $3,000 \times \mathrm{g}$ and $4^{\circ} \mathrm{C}$ for $15 \mathrm{~min}$. The supernatants were collected and the protein concentration was determined using a BCA protein assay kit (Beyotime Institute of Biotechnology). Protein samples (40 $\mu \mathrm{g})$ were loaded per lane and separated using 10\% SDS-PAGE (Beyotime Institute of Biotechnology). The target proteins, including phosphorylated Src, VE-cadherin and caveolin-1, 
were then electrophoretically transferred onto nitrocellulose membranes (Beyotime Institute of Biotechnology). The protein blots were blocked in Tris-Buffered Saline and Tween 20 (TBST; 5\% non-fat milk, $10 \mathrm{mM}$ Tris, $150 \mathrm{mM} \mathrm{NaCl}$, $0.05 \%$ Tweek-20) for $1 \mathrm{~h}$, followed by incubation with primary antibodies against phosphorylated Src (monoclonal; 1:200, rabbit anti-mouse; ab4816; Oncogene Research Products; La Jolla, CA, USA), phosphorylated VE-cadherin (polyclonal, 1:400; rabbit anti-mouse; SAB4504676; BD Biosciences, Franklin Lakes, NJ, USA), VE-cadherin (monoclonal; 1:400; rabbit anti-mouse; V1514; BD Biosciences), phosphorylated caveolin-1 (polyclonal, 1:400; rabbit anti-mouse; sc-14037; Santa Cruz Biotechnology Inc., Dallas, TX, USA) or caveolin-1 (monoclonal; 1:400; rabbit anti-mouse; sc-53564; Santa Cruz Biotechnology Inc.) overnight at $4^{\circ} \mathrm{C}$. Blots were then treated with the following secondary antibodies in TBST solution for $1 \mathrm{~h}$ : Secondary Src antibody [polyclonal; 1:4000; chicken anti-rabbit immunoglobulin G (IgG); ab6829; Abcam, Cambridge, MA, USA], phosphorylated VE-cadherin (polyclonal), VE-cadherin (monoclonal), phosphorylated caveolin-1 (polyclonal) or caveolin-1 (monoclonal; all 1:3,000; chicken anti-rat; ab112448; Abcam). Each sample was also probed with $\beta$-actin antibody $(1: 30,000$; rabbit anti-mouse; A53161; Sigma-Aldrich, St. Louis, MO, USA) as a loading control, and $\beta$-actin secondary antibody (monoclonal; 1:3,000; chicken anti-mouse IgG; ab131368, Abcam). Finally, blots were washed with PBS with Tween 20 and then examined using the ECL Plus Western Blotting Detection System (Amersham Life Science, Little Chalfont, Buckinghamshire, UK).

Statistical analysis. Values are presented as the mean \pm standard error of the mean. Statistical analysis was performed using SPSS 17.0 (SPSS, Inc., Chicago, IL, USA) with one-way analysis of variance followed by Student-Newman-Keuls post-hoc test. $\mathrm{P}<0.05$ was considered to indicate a statistically significant difference.

\section{Results}

PP2 attenuates the increase in pulmonary microvascular leakage in BALF following CPB. Fig. 1 shows alterations in pulmonary microvascular leakage over time demonstrated by the concentration of EBD. Pulmonary microvascular leakage increased up to $24 \mathrm{~h}$ after $\mathrm{CPB}$, but decreased at $48 \mathrm{~h}$ after CPB. Treatment with PP2 significantly inhibited the increase in pulmonary microvascular leakage compared with the $\mathrm{CPB}$ group $(\mathrm{P}<0.05)$. However, the $\mathrm{CPB}+\mathrm{PP} 2$ group exhibited increased pulmonary microvascular leakage $(\mathrm{P}<0.05)$ compared with the sham group with the exception of at $0 \mathrm{~h}$ after $\mathrm{CPB}$.

PP2 attenuates increases in the neutrophil count and proinflammatory cytokines, $I L-1 \beta$ and $I L-6$, in BALF following $C P B$. Fig. 2A shows alterations in the neutrophil count in BALF following CPB. The neutrophil count was increased following CPB surgery over time until $12 \mathrm{~h}$ after CPB. It peaked at 12 and $24 \mathrm{~h}$ after CPB and then decreased at $48 \mathrm{~h}$ after CPB. Treatment with PP2 significantly inhibited the increase in neutrophil count in BALF compared with the CPB group $(\mathrm{P}<0.05$, compared with the $\mathrm{CPB}$ group; $\mathrm{P}>0.05$,

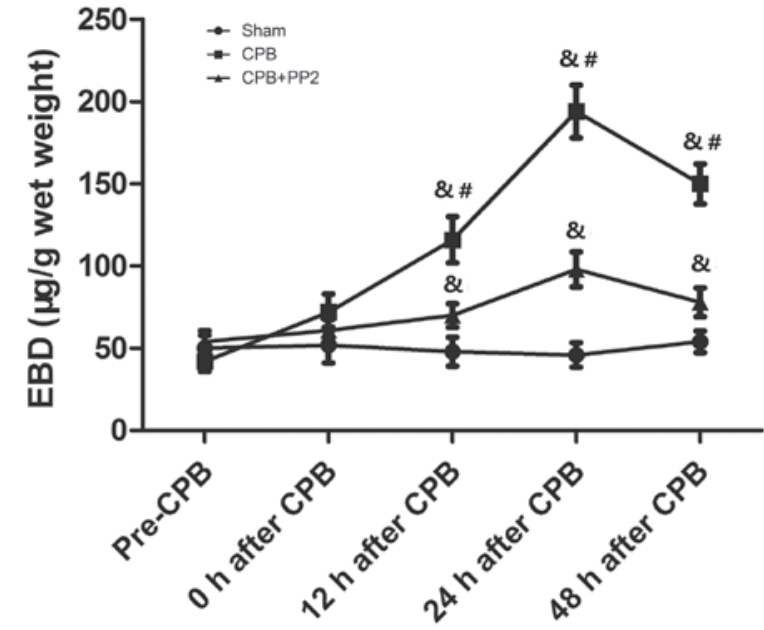

Figure 1. EBD concentration in BALF following CPB. Animals were sacrificed at different time points prior to or following CPB surgery (Pre-CPB, $0 \mathrm{~h}$ after $\mathrm{CPB}, 12 \mathrm{~h}$ after $\mathrm{CPB}, 24 \mathrm{~h}$ after $\mathrm{CPB}$ and $48 \mathrm{~h}$ after $\mathrm{CPB})$. In the $\mathrm{CPB}+\mathrm{PP} 2$ group, $1 \mathrm{mg} / \mathrm{kg} \mathrm{PP} 2$ was intraperitoneally injected $30 \mathrm{~min}$ prior to $\mathrm{CPB} .{ }^{\&} \mathrm{P}<0.05$, compared with the sham group; ${ }^{\#} \mathrm{P}<0.05$, compared with the CPB + PP2 group. EBD, Evans Blue Dye; BALF, bronchoalveolar lavage fluid; CPB, cardiopulmonary bypass; PP2, 4-amino-5-(4-chlorophenyl)-7-(di methylethyl)pyrazolo[3,4-d]pyrimidine.

compared to the sham group). No significant difference was observed between the sham group and the untreated group.

Fig. 2B-D show the results of TNF- $\alpha$, IL-1 $\beta$ and IL-6 in BALF. TNF- $\alpha$ partially increased following CPB surgery, continued increasing in the first $24 \mathrm{~h}$ and then decreased at $48 \mathrm{~h}$ after CPB. Treatment with PP2 did not alter post-surgical increases in TNF- $\alpha$. Unlike TNF- $\alpha$, IL-1 $\beta$ increased over time until $48 \mathrm{~h}$ after CPB. PP2 significantly inhibited the level of IL-1 $\beta$ compared with the CPB group $(\mathrm{P}<0.05)$, although it remained higher than the sham group $(\mathrm{P}<0.05)$. Alterations in IL- 6 concentration demonstrated a similar pattern with TNF- $\alpha$ and peaked at $24 \mathrm{~h}$ after CPB. PP2 significantly ameliorated the increase in IL-6 in BALF $(\mathrm{P}<0.05$, compared with the CPB group; $P>0.05$ compared with the sham group). No significant difference was identified between the sham group and untreated group.

Src phosphorylation increases in the lung tissues following $C P B$ surgery. Fig. 3 reveals the time course of Src phosphorylation in lung tissues. Src phosphorylation was not altered immediately following CPB surgery. However, Src phosphorylation increased at $12 \mathrm{~h}$ after CPB and peaked at $24 \mathrm{~h}$ after $\mathrm{CPB}(\mathrm{P}<0.05$, compared with the $12 \mathrm{~h}$ after $\mathrm{CPB}$ group). At $48 \mathrm{~h}$ after $\mathrm{CPB}$, it regressed to the normal level $(\mathrm{P}<0.05$, compared with 12 and $24 \mathrm{~h}$ after $\mathrm{CPB}$ ).

PP2 attenuates increases in caveolin-1 and VE-cadherin phosphorylation in the lung tissues following CPB. In order to examine the effect of Src kinase activation on caveolin-1 and VE-cadherin, caveolin-1 and VE-cadherin phosphorylation in the lung tissues was measured (Fig. 4). Caveolin-1 phosphorylation did not immediately change following CPB surgery, but significantly increased $(\mathrm{P}<0.05$, compared with the sham group) at $24 \mathrm{~h}$ after $\mathrm{CPB}$. Treatment with three doses of PP2 (1, 2 and $4 \mathrm{mg} / \mathrm{kg})$ inhibited caveolin-1 phosphorylation 
A

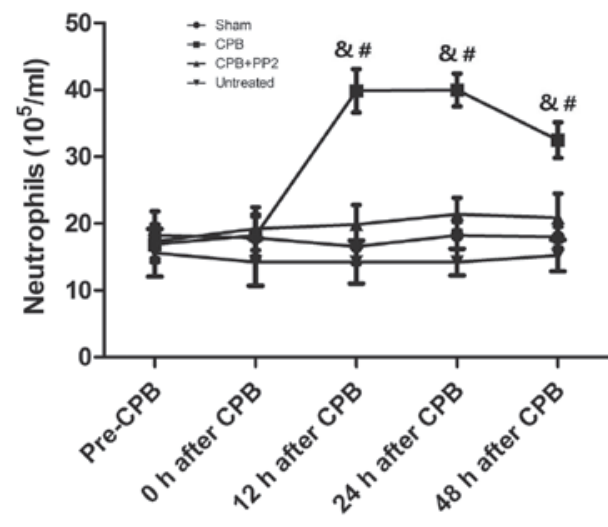

C

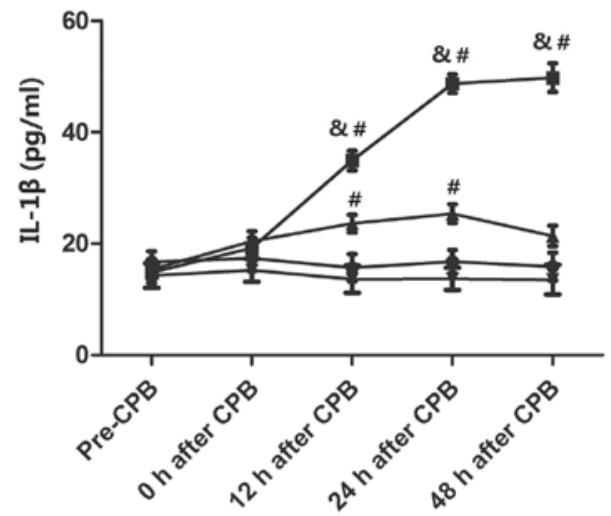

B

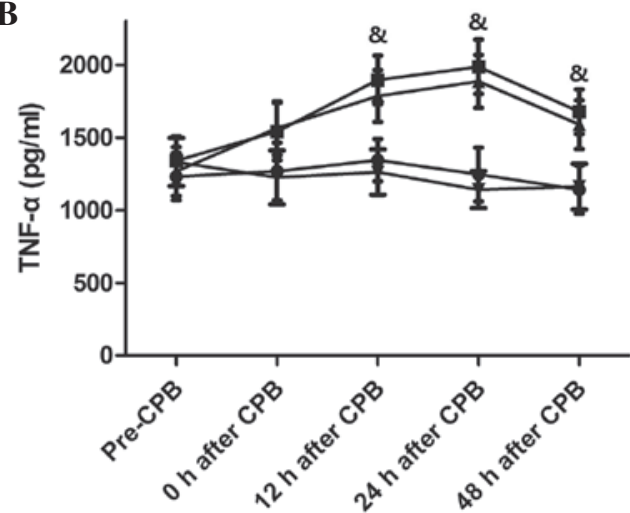

D

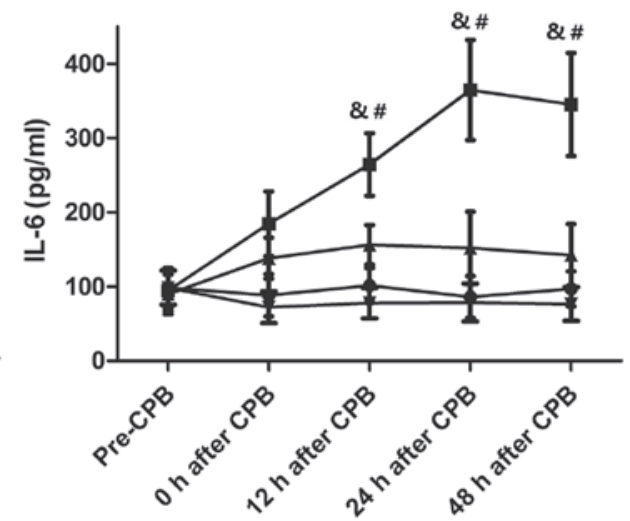

Figure 2. Neutrophil count and proinflammatory cytokines in BALF following CPB (treatments are described in Fig. 1). (A) Changes in the number of neutrophils in BALF. Expression levels of (B) TNF- $\alpha$, (C) IL-1 $\beta$ and (D) IL-6 in BALF. Values are expressed as the mean \pm standard error. $N=10$ per group. ${ }^{\circledR} \mathrm{P}<0.05$, compared with the sham group; ${ }^{\sharp} \mathrm{P}<0.05$, compared with the CPB + PP2 group. BALF, bronchoalveolar lavage fluid; CPB, cardiopulmonary bypass; IL, interleukin; TNF, tumor necrosis factor; PP2, 4-amino-5-(4-chlorophenyl)-7-(dimethylethyl)pyrazolo[3,4-d]pyrimidine.



Src

$\beta$-actin

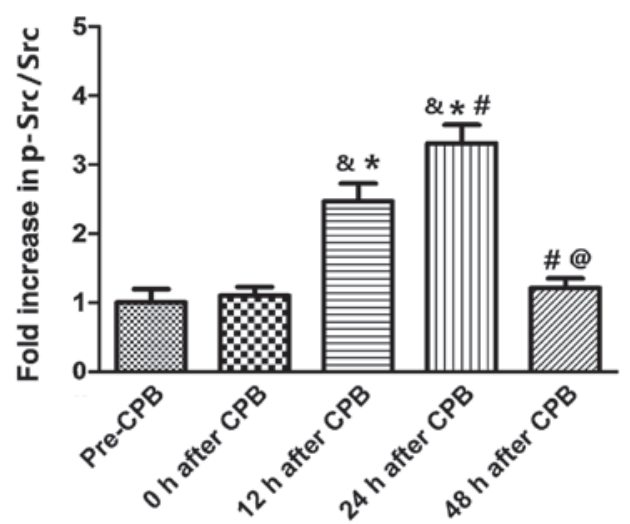

Figure 3. Western blot analysis of Src phosphorylation in the lung tissues. Treatments have been described in Fig. 1. ${ }^{\&} \mathrm{P}<0.05$, compared with the pre-CPB group; ${ }^{*} \mathrm{P}<0.05$, compared with $0 \mathrm{~h}$ after $\mathrm{CPB}$; ${ }^{*} \mathrm{P}<0.05$, compared with $12 \mathrm{~h}$ after $\mathrm{CPB} ;{ }^{\circledR} \mathrm{P}<0.05$ compared with $24 \mathrm{~h}$ after $\mathrm{CPB}$. $\mathrm{CPB}$, cardiopulmonary bypass. in a dose-dependent manner (Fig. 4A). No significant difference was observed in VE-cadherin phosphorylation between the sham group and at $0 \mathrm{~h}$ after $\mathrm{CPB}$ surgery. However, at $24 \mathrm{~h}$ after $\mathrm{CPB}$, VE-cadherin phosphorylation significantly increased $(\mathrm{P}<0.05)$ compared with the sham group. Treatment with high doses of PP2 (2 and $4 \mathrm{mg} / \mathrm{kg}$ ) significantly inhibited VE-cadherin phosphorylation (Fig. 4B).

\section{Discussion}

Acute lung injury is among the leading cause of morbidity and mortality in patients who have undergone cardiac surgery necessitating CPB $(19,20)$. Numerous factors may contribute to acute lung injury, including the exposure of blood to the artificial surface of the CPB machine, ischemia-reperfusion and lung ventilator-elicited inflammatory reactions (21). Certain previous studies have suggested that pulmonary microvascular permeability is a major contributor to acute lung injury $(22,23)$, however, the mechanisms have not yet been investigated. In the present study, the EBD results indicated impaired pulmonary microvascular permeability following CPB surgery. The microvascular permeability started to increase following CPB surgery and then peaked $24 \mathrm{~h}$ later. $\mathrm{CPB}$ also induced significant increases in the neutrophil count and TNF- $\alpha$, IL-1 $\beta$ and IL-6 in BALF, indicating the provoked inflammatory reaction and increased pulmonary microvascular permeability. Neutrophils, TNF- $\alpha$ 
A
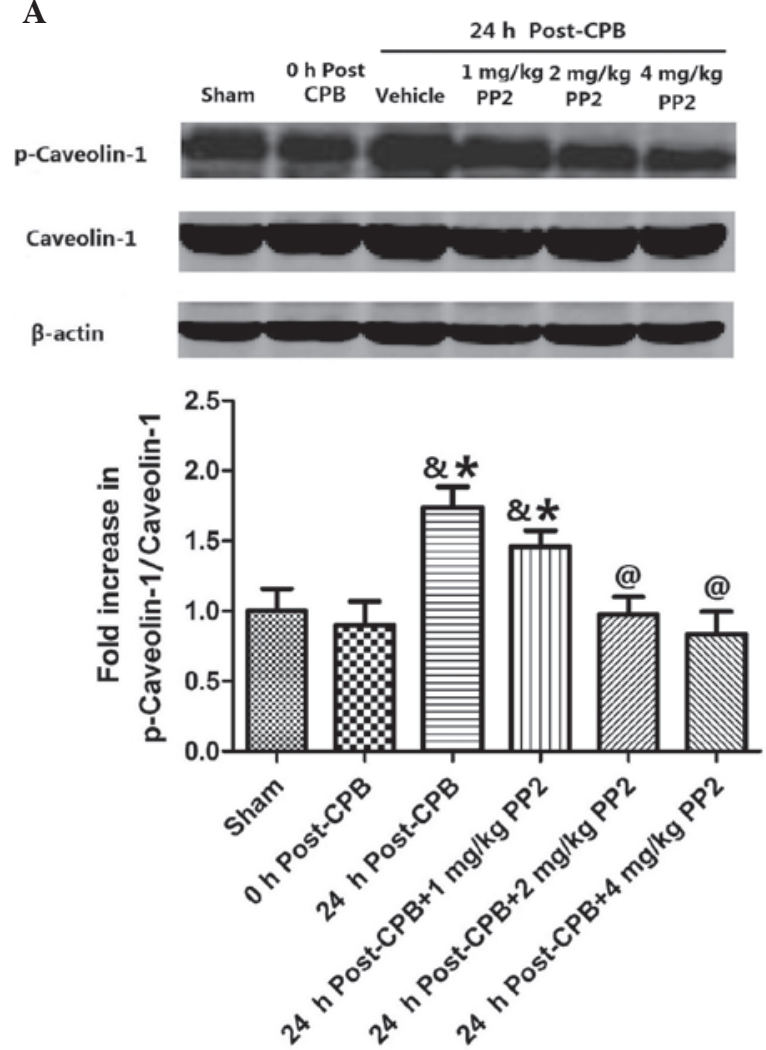
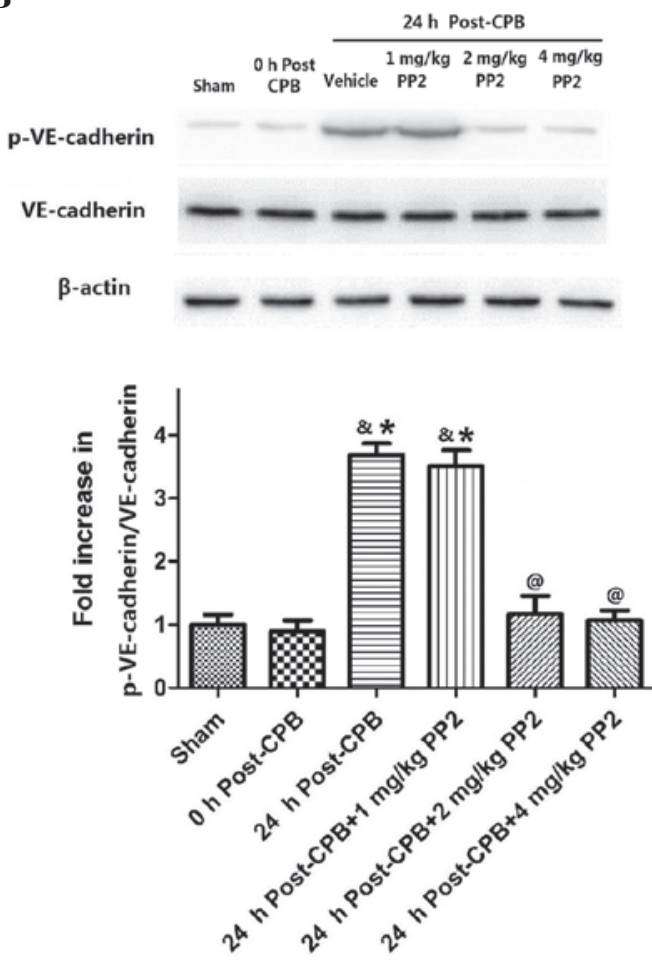

Figure 4. Caveolin-1 and VE-cadherin phosphorylation in the lung tissues. (A) Changes of caveolin-1 and (B) VE-cadherin photophosphorylation. Values are expressed as the mean \pm standard error. $\mathrm{N}=10$ per group. ${ }^{\circledR} \mathrm{P}<0.05$, compared with the sham group; ${ }^{*} \mathrm{P}<0.05$, compared with the $0 \mathrm{~h}$ post $\mathrm{CPB}$ group; ${ }^{\circledR} \mathrm{P}<0.05$, compared with the $24 \mathrm{~h}$ post $\mathrm{CPB}+1 \mathrm{mg} / \mathrm{kg}$ PP2 group. VE-cadherin, vascular endothelial cadherin; CPB, cardiopulmonary bypass; PP2, 4-amino-5-(4-chlo rophenyl)-7-(dimethylethyl)pyrazolo[3,4-d]pyrimidine.

and IL-6 in BALF reached a peak at $24 \mathrm{~h}$ post CPB, while IL-1 $\beta$ in BALF continued to increase until $48 \mathrm{~h}$ post CPB. These data revealed the time course of the inflammatory reaction, which emerged following CPB surgery and peaked at 24-48 $\mathrm{h}$ after CPB surgery. The time course of these changes correlates with the alterations in pulmonary microvascular permeability.

Src kinases belong to the non-receptor tyrosine kinase family, which contains c-Src, Fyn, Yes, Yrk, Blk, Fgr, Hck, Lck and Lyn (24). In response to stimulation of a variety of cell surface receptors, including tyrosine kinase receptors, integrin receptors and G protein-coupled receptors, the activity of Src can be upregulated by phosphorylation at Tyr 416 , located in the catalytic domain (24). It has been demonstrated that Src mediates vascular endothelial permeability responses to TNF, reactive oxygen species, angiogenesis and vascular leakage (25-27). Inhibition of the Src family reduces cerebral edema and eradicates the increase in albumin permeability caused by C5 $\alpha$-activated neutrophils in venules $(28,29)$. Neutrophil activation stimulates Src phosphorylation at Tyr 416 and decreases phosphorylation at Tyr 527, which upregulates Src activity (30). The results demonstrated that Src phosphorylation (activation) accompanied the increase in pulmonary microvascular leakage, while the administration of PP2, an inhibitor of the Src kinase, attenuated the alterations in pulmonary microvascular leakage, neutrophil count and proinflammatory cytokines (with the exception of TNF- $\alpha$ ) in BALF caused by CPB, indicating that Src kinase has an important role in the effects of $\mathrm{CPB}$ on pulmonary microvascular permeability. For neutrophils and IL-6 in BALF, PP2 administration reduced their values to a level equivalent to the sham group. However, the fact that TNF- $\alpha$ was unaltered by PP2 suggests that the induction of TNF- $\alpha$ may not be regulated by Src kinase.

Src kinase may regulate the microvascular permeability and endothelial barrier structure through multiple pathways, including mitogen-activated protein kinase, myosin light chain kinase, $\beta$-catenin, or focal adhesion proteins $(24,31,32)$. The present study focused on caveolin-1 and VE-cadherin, two important proteins in the regulation of pulmonary microvascular permeability. Caveolae were originally identified as 50-100 nm flask-shaped, non-clathrin-coated invaginations of the plasma membrane, which are important in transendothelial vesicular transport. Caveolin-1 is a critical protein for caveolae-mediated endocytosis and transcytosis in endothelial cells (33). It contains a scaffolding domain and acts as an inhibitory regulator of endothelial Rac1 signaling in the regulation of endothelial permeability $(34,35)$. Tyrosine phosphorylation of caveolin-1 is important in the pathogenesis of oxidant-induced pulmonary vascular hyperpermeability (36). Previous studies have demonstrated that an increase in transcellular permeability was dependent on Src-mediated phosphorylation of caveolin-1 $(13,34,37,38)$. The pulmonary vascular hyperpermeability induced by activation of neutrophils adherent to the vessel wall is dependent on signaling via caveolin-1 and increased caveolae-mediated transcytosis (39). Sun et al demonstrated that phosphorylation of caveolin-1 is an important mechanism 
mediating oxidant-induced vascular hyperpermeability by stimulating paracellular and caveolae-mediated transcellular permeability (36). The results from the present study demonstrated that caveolin-1 phosphorylation was not altered immediately following CPB surgery, but was significantly increased at $24 \mathrm{~h}$ after CPB. Treatment with $1 \mathrm{mg} / \mathrm{kg}$ PP2 did not alter caveolin-1 phosphorylation, however, 2 and $4 \mathrm{mg} / \mathrm{kg}$ PP2 inhibited caveolin-1 phosphorylation, indicating that Src kinase may function via the activation of caveolin-1.

VE-cadherin is a classical cadherin from the cadherin family, which is critical in endothelial cell biology and vascular permeability through homophilic binding to other VE-cadherins expressed on adjacent endothelial cells (40). Numerous stimuli, including TNF and vascular endothelial growth factor, may cause the phosphorylation of VE-cadherin, in which Src kinase acts as a key pathway mediator $(14,41)$. It was also demonstrated that proinflammatory cytokines could induce the phosphorylation of VE-cadherin and the endocytosis of VE-cadherin in a $\beta$-arrestin-dependent manner through the Src kinase pathway (42). Src activation could also cause the phosphorylation of VE-cadherin by stimulation of $\mathrm{H}_{2} \mathrm{O}_{2}(43,44)$. The present study demonstrated that VE-cadherin phosphorylation was not altered immediately following CPB surgery, however, it significantly increased at $24 \mathrm{~h}$ post CPB. VE-cadherin phosphorylation was inhibited by treatment with PP2 (2 and $4 \mathrm{mg} / \mathrm{kg}$ ). The results revealed that Src was involved in the phosphorylation of VE-cadherin, however, whether caveolin-1 mediated this process or not remains to be elucidated. A previous study demonstrated that the knockdown of caveolin-1 induced a decrease in VE-cadherin localized at inter-endothelial junctions (45). The interaction of caveolin-1 and VE-cadherin activation in Src-mediated pulmonary vascular hyperpermeability requires further investigation.

In conclusion, the present study demonstrated that pulmonary microvascular permeability was increased following CPB through the Src kinase pathway. The activation of caveolin-1 and VE-cadherin appears to be the downstream effect of Src kinase phosphorylation. Inhibition of this pathway may provide a potential therapy for acute lung injury following cardiac surgery.

\section{Acknowledgements}

This study was funded by the Science and Technology Commission of Shanghai Municipality (grant no. 11ZR1423700).

\section{References}

1. Gibbon JH Jr: Application of a mechanical heart and lung apparatus to cardiac surgery. Minn Med 37: 171-185, 1954.

2. Edmunds LH Jr: Advances in the heart-lung machine after John and Mary Gibbon. Ann Thorac Surg 76: S2220-S2223, 2003.

3. Wahba A: Centrifugal blood pump use in routine cardiac surgery. Interact Cardiovasc Thorac Surg 5: 299-300, 2006.

4. Cox CS Jr, Allen SJ and Brennan MS: Analysis of intestinal microvascular permeability associated with cardiopulmonary bypass. J Surg Res 83: 19-26, 1999.

5. Ng CS, Wan S, Yim AP and Arifi AA: Pulmonary dysfunction after cardiac surgery. Chest 121: 1269-1277, 2002.

6. Serraf A, Aznag H, Baudet B, Détruit H, Séccatore F, Mazmanian MG and Planché C: Pulmonary vascular endothelial growth factor and nitric oxide interaction during total cardiopulmonary bypass in neonatal pigs. J Thorac Cardiovasc Surg 125: 1050-1057, 2003.
7. Okutani D, Lodyga M, Han B and Liu M: Src protein tyrosine kinase family and acute inflammatory responses. Am J Physiol Lung Cell Mol Physiol 291: L129-L141, 2006.

8. Oyaizu T, Fung SY, Shiozaki A, Guan Z, Zhang Q, dos Santos CC, Han B, Mura M, Keshavjee S and Liu M: Src tyrosine kinase inhibition prevents pulmonary ischemia-reperfusion-induced acute lung injury. Intensive Care Med 38: 894-905, 2012.

9. Miyahara T, Hamanaka K, Weber DS, Drake DA, Anghelescu M and Parker JC: Phosphoinositide 3-kinase, Src and Akt modulate acute ventilation-induced vascular permeability increases in mouse lungs. Am J Physiol Lung Cell Mol Physiol 293: L11-L21, 2007.

10. Liu YY, Li LF, Fu JY, Kao KC, Huang CC, Chien Y, Liao YW, Chiou SH and Chang YL: Induced pluripotent stem cell therapy ameliorates hyperoxia-augmented ventilator-induced lung injury through suppressing the Src pathway. PLoS One 9: e109953, 2014.

11. Anderson RG: The caveolae membrane system. Annu Rev Biochem 67: 199-225, 1998.

12. Cohen A, Hnasko R, Schubert W and Lisanti MP: Role of caveolae and caveolins in health and disease. Physiol Rev 84: 1341-1379, 2004.

13. Minshall RD, Tiruppathi C, Vogel SM and Malik AB: Vesicle formation and trafficking in endothelial cells and regulation of endothelial barrier function. Histochem Cell Biol 117: 105-112, 2002.

14. Dejana E, Orsenigo F and Lampugnani MG: The role of adherens junctions and VE-cadherin in the control of vascular permeability. J Cell Sci 121: 2115-2122, 2008.

15. Orsenigo F, Giampietro C, Ferrari A, Corada M, Galaup A, Sigismund S, Ristagno G, Maddaluno L, Koh GY, Franco D, et al: Phosphorylation of VE-cadherin is modulated by haemodynamic forces and contributes to the regulation of vascular permeability in vivo. Nat Commun 3: 1208, 2012.

16. Institute of Laboratory Animal Resources (US). Committee on Care, Use of Laboratory Animals, and National Institutes of Health (US). Division of Research Resources: Guide for the care and use of laboratory animals. 7th edition. National Academies Press, Washington, DC, 1996.

17. Zhu J, Yin R, Shao H, Dong G, Luo L and Jing H: N-acetylcysteine to ameliorate acute renal injury in a rat cardiopulmonary bypass model. J Thorac Cardiovasc Surg 133: 696-703, 2007.

18. Cavriani G, Oliveira-Filho RM, Trezena AG, da Silva ZL, Domingos HV, de Arruda MJ, Jancar S and Tavares de Lima W: Lung microvascular permeability and neutrophil recruitment are differently regulated by nitric oxide in a rat model of intestinal ischemia-reperfusion. Eur J Pharmacol 494: 241-249, 2004.

19. Altmay E, Karaca P, Yurtseven N, Ozkul V, Aksoy T, Ozler A and Canik S: Continuous positive airway pressure does not improve lung function after cardiac surgery. Can J Anaesth 53: 919-925, 2006.

20. Apostolakis E, Filos KS, Koletsis E and Dougenis D: Lung dysfunction following cardiopulmonary bypass. J Card Surg 25: 47-55, 2010.

21. Engels M, Bilgic E, Pinto A, Vasquez E, Wollschläger L, Steinbrenner H, Kellermann K, Akhyari P, Lichtenberg A and Boeken U: A cardiopulmonary bypass with deep hypothermic circulatory arrest rat model for the investigation of the systemic inflammation response and induced organ damage. J Inflamm (Lond) 11: 26, 2014.

22. Macnaughton PD, Braude S, Hunter DN, Denison DM and Evans TW: Changes in lung function and pulmonary microvascular permeability after cardiopulmonary bypass. Crit Care Med 20: 1289-1294, 1992.

23. Messent M, Sinclair DG, Quinlan GJ, Mumby SE, Gutteridge JM and Evans TW: Pulmonary vascular permeability after cardiopulmonary bypass and its relationship to oxidative stress. Crit Care Med 25: 425-429, 1997.

24. Thomas SM and Brugge JS: Cellular functions regulated by Src family kinases. Annu Rev Cell Dev Biol 13: 513-609, 1997.

25. Kevil CG, Okayama N and Alexander JS: $\mathrm{H}(2) \mathrm{O}(2)$-mediated permeability II: Importance of tyrosine phosphatase and kinase activity. Am J Physiol Cell Physiol 281: C1940-C1947, 2001.

26. Nwariaku FE, Liu Z, Zhu X, Turnage RH, Sarosi GA and Terada LS: Tyrosine phosphorylation of vascular endothelial cadherin and the regulation of microvascular permeability. Surgery 132: 180-185, 2002.

27. Eliceiri BP, Paul R, Schwartzberg PL, Hood JD, Leng J and Cheresh DA: Selective requirement for Src kinases during VEGF-induced angiogenesis and vascular permeability. Mol Cell 4: 915-924, 1999. 
28. Paul R, Zhang ZG, Eliceiri BP, Jiang Q, Boccia AD, Zhang RL, Chopp $M$ and Cheresh DA: Src deficiency or blockade of Src activity in mice provides cerebral protection following stroke. Nat Med 7: 222-227, 2001

29. Tinsley JH, Ustinova EE, Xu W, Yuan SY: Src-dependent, neutrophil-mediated vascular hyperpermeability and beta-catenin modification. Am J Physiol Cell Physiol 283: 1745-1751, 2002.

30. Yuan SY: Protein kinase signaling in the modulation of microvascular permeability. Vascul Pharmacol 39: 213-223, 2002.

31. Eliceiri BP, Puente XS, Hood JD, Stupack DG, Schlaepfer DD, Huang XZ, Sheppard D and Cheresh DA: Src-mediated coupling of focal adhesion kinase to integrin alpha(v)beta5 in vascular endothelial growth factor signaling. J Cell Biol 157: 149-160, 2002.

32. Shi S, Garcia JG, Roy S, Parinandi NL and Natarajan V: Involvement of c-Src in diperoxovanadate-induced endothelial cell barrier dysfunction. Am J Physiol Lung Cell Mol Physiol 279: L441-L451, 2000.

33. Drab M, Verkade P, Elger M, Kasper M, Lohn M, Lauterbach B, Menne J, Lindschau C, Mende F, Luft FC, et al: Loss of caveolae, vascular dysfunction and pulmonary defects in caveolin-1 gene-disrupted mice. Science 293: 2449-2452, 2001.

34. Minshall RD, Sessa WC, Stan RV, Anderson RG and Malik AB: Caveolin regulation of endothelial function. Am J Physiol Lung Cell Mol Physiol 285: L1179-L1183, 2003.

35. Gonzalez E, Nagiel A, Lin AJ, Golan DE and Michel T: Small interfering RNA-mediated down-regulation of caveolin-1 differentially modulates signaling pathways in endothelial cells. J Biol Chem 279: 40659-40669, 2004

36. Sun Y, Hu G, Zhang X and Minshall RD: Phosphorylation of caveolin-1 regulates oxidant-induced pulmonary vascula permeability via paracellular and transcellular pathways. Circ Res 105: 676-685, 2009.
37. Shajahan AN, Timblin BK, Sandoval R, Tiruppathi C, Malik AB and Minshall RD: Role of Src-induced dynamin-2 phosphorylation in caveolae-mediated endocytosis in endothelial cells. J Biol Chem 279: 20392-20400, 2004.

38. Minshall RD, Tiruppathi C, Vogel SM, Niles WD, Gilchrist A, Hamm HE and Malik AB: Endothelial cell-surface gp60 activates vesicle formation and trafficking via Gi-coupled Src kinase signaling pathway. J Cell Biol 150: 1057-1070, 2000.

39. Hu G, Vogel SM, Schwartz DE, Malik AB and Minshall RD: Intercellular adhesion molecule-1-dependent neutrophil adhesion to endothelial cells induces caveolae-mediated pulmonary vascular hyperpermeability. Circ Res 102: e120-e131, 2008

40. Lim MJ, Chiang ET, Hechtman HB and Shepro D: Inflammation-induced subcellular redistribution of VE-cadherin, actin and gamma-catenin in cultured human lung microvessel endothelial cells. Microvasc Res 62: 366-382, 2001.

41. Gavard J, Hou X, Qu Y, Masedunskas A, Martin D, Weigert R, Li X and Gutkind JS: A role for a CXCR2/phosphatidylinositol 3-kinase gamma signaling axis in acute and chronic vascular permeability. Mol Cell Biol 29: 2469-2480, 2009.

42. Gavard J and Gutkind JS: VEGF controls endothelial-cell permeability by promoting the beta-arrestin-dependent endocytosis of VE-cadherin. Nat Cell Biol 8: 1223-1234, 2006.

43. Mehta D and Malik AB: Signaling mechanisms regulating endothelial permeability. Physiol Rev 86: 279-367, 2006.

44. Aberle H, Schwartz HR and Kemler R: Cadherin-catenin complex: Protein interactions and their implications for cadherin function. J Cell Biochem 61: 514-523, 1996.

45. Song L, Ge S and Pachter JS: Caveolin-1 regulates expression of junction-associated proteins in brain microvascular endothelial cells. Blood 109: 1515-1523, 2007. 